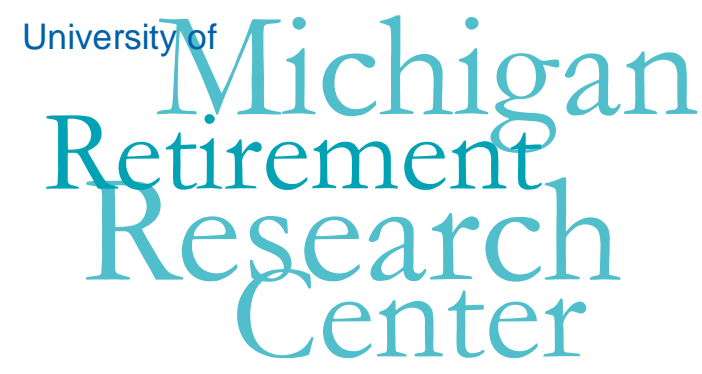

Working Paper

WP 2010-224

\title{
Health and Wealth in a Life Cycle Model
}

\author{
John Karl Scholz and Ananth Seshadri
}

\begin{tabular}{|l|l|}
\hline $\mathrm{M}$ & $\mathrm{R}$ \\
\hline $\mathrm{R}$ & $\mathrm{C}$ \\
\hline
\end{tabular}

Project \#: UM10-19 


\title{
Health and Wealth in a Life Cycle Model
}

\author{
John Karl Scholz \\ University of Wisconsin-Madison \\ Ananth Seshadri \\ University of Wisconsin-Madison \\ September 2010
Michigan Retirement Research Center
University of Michigan
P.O. Box 1248
Ann Arbor, MI 48104
http://www.mrrc.isr.umich.edu/ \\ (734) 615-0422
}

\section{Acknowledgements}

This work was supported by a grant from the Social Security Administration through the Michigan Retirement Research Center (Grant \# 10-M-98362-5-01). The findings and conclusions expressed are solely those of the author and do not represent the views of the Social Security Administration, any agency of the Federal government, or the Michigan Retirement Research Center.

\section{Regents of the University of Michigan}

Julia Donovan Darrow, Ann Arbor; Laurence B. Deitch, Bingham Farms; Denise Ilitch, Bingham Farms; Olivia P. Maynard, Goodrich; Andrea Fischer Newman, Ann Arbor; Andrew C. Richner, Grosse Pointe Park; S. Martin Taylor, Gross Pointe Farms; Katherine E. White, Ann Arbor; Mary Sue Coleman, ex officio 


\title{
Health and Wealth in a Life Cycle Model
}

\begin{abstract}
This paper presents a preliminary model of health investments over the life cycle. Health affects both longevity and provides flow utility. We analyze the interplay between consumption choices and investments in health by solving each household's dynamic optimization problem to obtain predictions on health investments and consumption choices over the lifecycle. Our preliminary model does a good job of matching the distribution of medical expenses across households in the sample. We illustrate the scope of future model applications by examining the effects of a stylized Medicare program on patterns of wealth and mortality.
\end{abstract}

\section{Authors' Acknowledgements}

The research reported herein was pursuant to a grant from the U.S. Social Security Administration (SSA) funded as part of the Retirement Research Consortium (RRC). The findings and conclusions expressed are solely those of the authors and do not represent the views of SSA, any agency of the Federal Government or the RRC. We are also grateful to the NIH for generous financial support through grant R01AG032043. Mike Anderson provided fine research assistance. 


\section{Introduction}

Health and consumption decisions are interlinked, yet the ways that consumption and health interact are hard to untangle. Health changes, such as disability or illness, affect labor market decisions and hence income and consumption possibilities. But causality undoubtedly also operates in the other direction, where consumption decisions such as smoking or exercise affect health. Moreover, there are also likely unobserved differences between people in their ability to produce and maintain health and human capital, leading to correlations between health and lifetime income and wealth. This paper examines links between health, consumption and wealth.

There are many ways to examine these links. Our analysis starts from ideas dating back at least to Grossman (1972), who argued that health is the cumulative result of investment and choices (along with randomness) that begin in utero. We model household utility as being a function of consumption and health, where individuals make optimizing decisions over the production of health along with consumption. Surprisingly, given the obvious centrality of health to economic decision-making and well-being, numerical models of lifecycle consumption choices generally treat health in a highly stylized fashion. The most common approach in papers, including Hubbard, Skinner, and Zeldes (1995); Engen, Gale, Uccello (1999); Palumbo (1999); Scholz, Seshadri, Khitatrakun (2006); and Kopecky and Koreshkova (2009) ignore health as an argument of utility. Instead lifetime budgets are subject to medical expense shocks that proxy for health shocks. Households respond to exogenous medical expense shocks by decreasing consumption and by saving for precautionary reasons.

This paper describes our initial efforts to formulate a life-cycle model that we solve household-by-household, where health investments (including time-use decisions) can affect longevity. By modeling investments in health, longevity becomes an endogenous outcome, which allows us to study the effects of changes in safety net policy, for example, 
on mortality as well as wealth.

The strong link observed in data between income (and wealth) and longevity is sometimes referred to as the wealth-health (or income-health) gradient. As we discuss below, the factors driving the gradient are unclear and remain controversial. We do not resolve questions about the factors driving the wealth-health gradient. But our model captures the effects that lifetime income has on health investments and mortality, which allows us to examine how much of the gradient of mortality with respect to lifetime income in the United States can be explained by our model. We also highlight the effects that health investment have on patterns of wealth accumulation around the time of retirement and at death.

To summarize, we examine the links between lifetime income and health by specifying an economic environment, preferences, expectations, and parameters that match key features of the underlying data. We then explore how changes in the economic environment and other aspects of the model affect key outcomes, such as longevity and wealth. In doing so, we highlight mechanisms affecting health and wealth that have received little attention in the literature.

Prior work that does not fully account for health in intertemporal models of consumption may yield incomplete or erroneous implications. For example, the effects of income transfers on consumption may be overstated in the consumption-smoothing literature: in the absence of safety net expenditures, households might maintain consumption at the cost of activities that degrade health and consequently affect longevity. These health-reducing activities might include working an additional job (and foregoing sleep); foregoing exercise; or eating high-calorie, inexpensive fast food rather than healthier home-cooked meals. Over the long run, effects can be large. In a world without health-related social insurance, young forward-looking households may recognize the futility of accumulating wealth to offset expected late-in-life health shocks and simply enjoy a higher standard of living for a shorter expected life. Depending on lifetime 
earnings or the economic environment, other households may sharply increase precautionary saving in a world without health-related social insurance. Our model provides quantitative insight about these responses.

We, of course, are not the first to examine the links between health, consumption, and wealth. Clear discussions are given in Smith (2005) and Case and Deaton (2005) and many other places. More closely related to our work is an important set of papers, including Palumbo (1999); Kopecky and Koreshkova (2009); and De Nardi, French and Jones (2010) that document the substantial role that late-in-life health shocks, including nursing home expenses and social insurance, play in old age wealth decumulation. While these papers offer valuable insights, they fall short of capturing the varied ways that health and consumption interact in the Grossman framework. In particular, except for the model with exogenous medical expense shocks in Section 9 of De Nardi, French and Jones (2010), the only response that households have to the realization of medical expense shocks in these models is to alter consumption. Death occurs through the application of life tables with random longevity draws.

De Nardi, French and Jones (2010) write down and estimate key structural parameters of a model where consumption and medical expenditures are arguments of utility, and where health status and age affect the size of medical-needs shocks. ${ }^{1}$ Their model is estimated on a sample of single individuals age 70 and over. They find that endogenizing medical expense shocks has little effect on their results: they write "In sum, the endogenous medical expense model confirms and reinforces our conclusion that medical expenses are a major saving motive and that social insurance affects the saving of the income-rich as well as that of the income-poor. Our main findings appear robust to

\footnotetext{
${ }^{1}$ Two other related papers model intertemporal consumption decisions and include health in the utility function. Fonseca, Michaud, Galama, and Kapteyn (2009) write down a model similar to ours and solve the decision problem for 1,500 representative households. Consumption and health are separable in utility in their model and the focus of their work is on explaining the causes behind the increases in health spending and life expectancy between 1965-2005. Yogo (2009) solves a model similar to ours for retired, single women over 65 to examine portfolio choice and annuitization in retirement.
} 
the way in which we model the medical expense decision." As De Nardi et al. note, medical expenditures beyond those provided by Medicaid, Medicare, and private insurance policies may contribute little to overall health. Moreover, health capital may be well-formed by prior decisions and expenditures by the time an individual reaches age 70.

We build on the innovative endogenous medical expense model of De Nardi, French and Jones (2010) in three ways. First, we model the process of health production starting at the beginning of working life. Health is undoubtedly influenced by shocks and decisions even made in utero and in childhood. But forward-looking households will respond to income shocks, health shocks, or to changes in institutions by altering their health investments and consumption during their working lives. Second, as De Nardi, French and Jones (2010) and many others note, the contribution of out-ofpocket medical expenditures on health, particularly late in life, are likely minimal. Yet even in the United States, there is a strong, positive gradient between income/wealth and health/mortality. It is possible that broadly defined health expenditures, such as smoking decisions, exercise, diet, and preventative medical care (such as consumption of beta-blockers and cholesterol drugs) indeed affect health and longevity. While our approach is stylized, we take a more expansive view than prior work of health investments. ${ }^{2}$

A third distinction is perhaps most important. De Nardi, French and Jones (2010), Kopecky and Koreshkova (2009) and others have shown that anticipated and realized medical expenses are an important determinant of wealth decumulation patterns in old age. The focus of our work differs. We develop a model of wealth and longevity in order to study how health shocks affect consumption plans, as done by others in the literature, and investments in "health capital." If death occurs when health falls below

\footnotetext{
${ }^{2}$ As the project develops, we will do more to address other factors that contribute to the healthwealth gradient, such as the effect that health status has on income, and the likelihood that unobserved factors influence both human capital and health production.
} 
a given threshold, households may respond to policy or exogenous shocks by reducing or increasing consumption and hence altering longevity relative to a world where health is not an argument in preferences. Studying the tradeoff between consumption and health investments on longevity (and health status) offers new insights into household behavior.

\section{Descriptive Evidence}

We use data from three waves of the Health and Retirement Study, 1998, 2000, and 2002. Given these waves, the sample includes households from the AHEAD cohort, born before 1924; Children of Depression Age (CODA) cohort, born between 1924 and 1930; the original HRS cohort, born between 1931 and 1941; and the War Baby cohort, born between 1942 and 1947. The sample is a representative, randomly stratified sample of U.S. households born before 1947. The HRS modestly oversamples blacks, Hispanics, and Floridians.

There is a strong relationship between lifetime income and survival in the HRS. To show this, we restrict the sample to birth years that, in principle, would allow someone to reach a specific age by the last year of HRS data we have available, 2006. So, for example, when we look at patterns of survival to age 70 , we restrict the sample to those born before 1936. We also drop all sample members who were over 65 years old in the year they entered the HRS sample. When we look at survival to age 85, we condition the sample to those born before 1921 and drop those who were older than 80 in the year they entered the HRS sample. At this stage of our analysis, we also restrict the sample to couples where at least one member allowed researchers to gain access to their social security earnings records (under tightly controlled conditions). Our samples for survival to age 70 has 4,724 individuals, our sample for survival to age 85 has 2,118 individuals. 


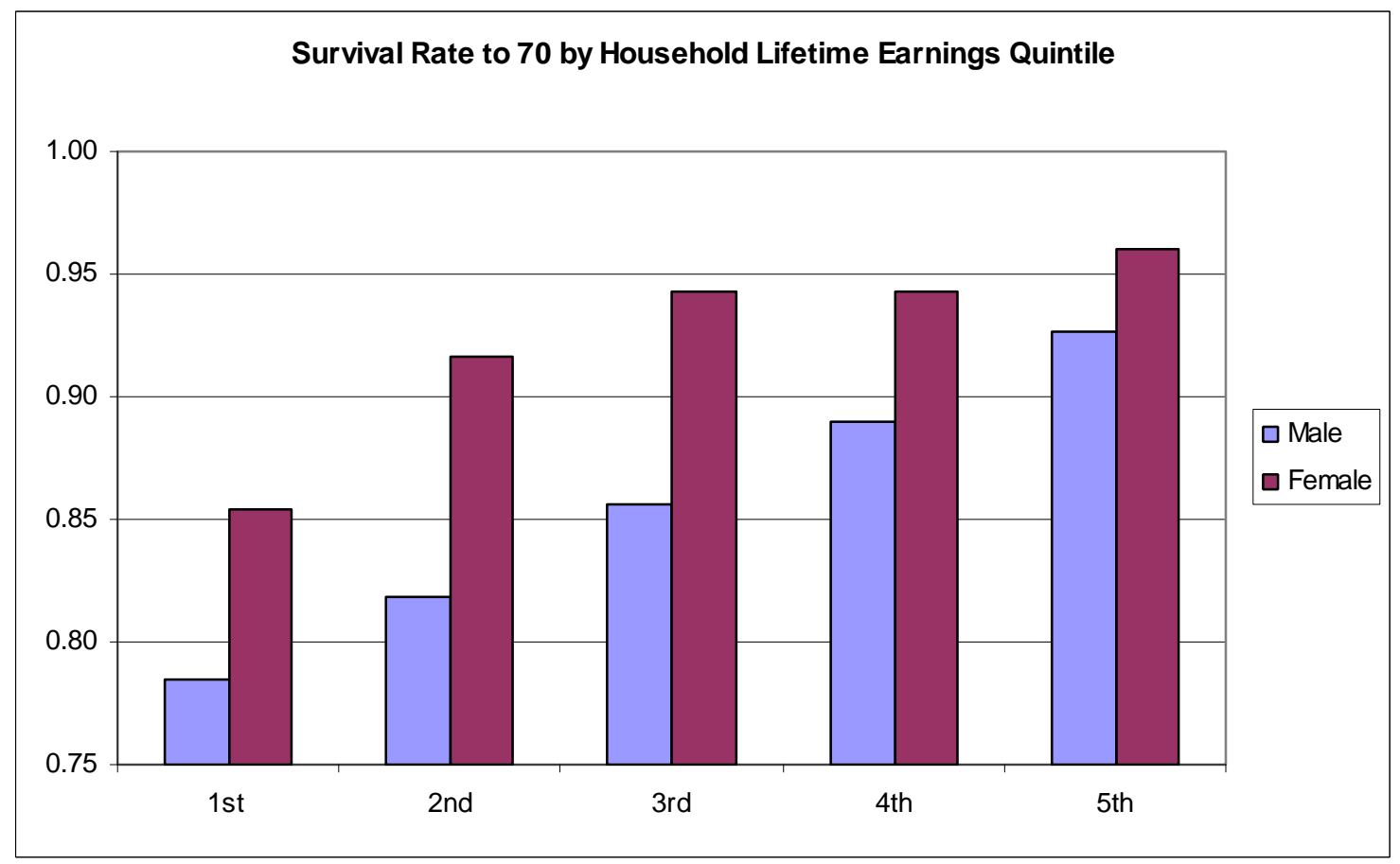

Our results on survival probabilities to age 70, tabulated by lifetime income quintile, match expectations. For men, the survival probabilities increase monotonically with lifetime income, from 78 percent for those in the lowest lifetime income quintile to 92 percent for those in the highest. The gradient is apparent but less strong for women, where survival probabilities increase from 85 percent in the lowest lifetime income quintile to 96 percent in the highest.

Differential mortality by lifetime income plays a much larger role in the patterns of survival to age 85 by lifetime income, which are shown below. Here it appears that differential mortality by socioeconomic status has an important effect on data patterns. Specifically, men in the lowest lifetime income quintile and women in the bottom two lifetime income quintiles die at an early enough age to never appear in the analysis sample for surviving to age 85. This leaves the survivors in the low lifetime income quintiles stronger, healthier than the typical household prior to the within-quintile mortality. The patterns for males is nevertheless striking: men in the highest lifetime income decile are 
almost twice as likely to live to age 85 as those in the second lifetime income quintile. As with the previous figure, the gradient exists but is less strong for women. The two figures suggest that in the raw, unconditional data, there is a fairly strong positive relationship between survival and lifetime income, though the relationship is stronger for men than it is for women.

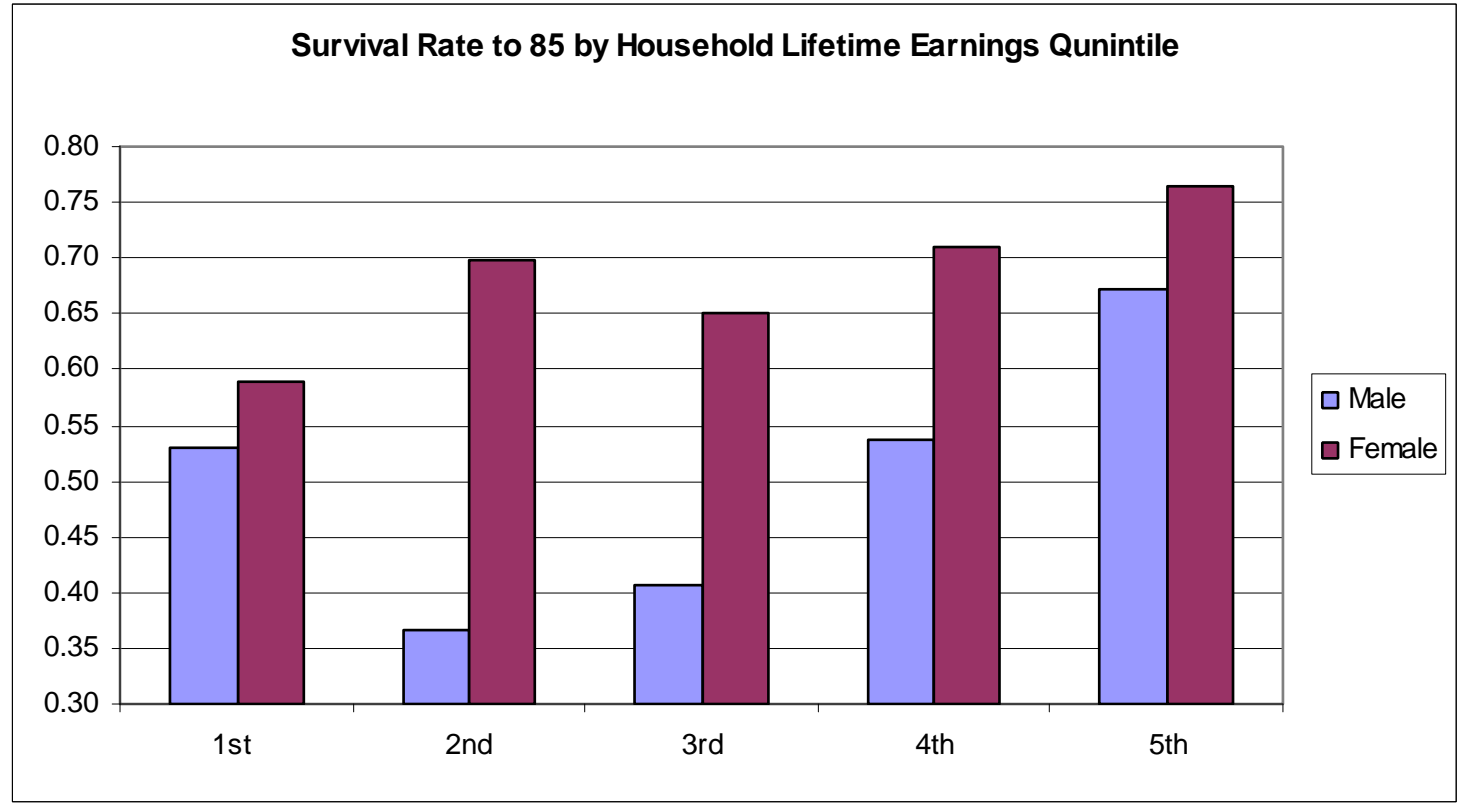

These patterns are consistent with several potential explanations. Income may affect health. The gradient may be the result of education or discount rates, which affect health behaviors as well as labor market experience. The gradient may be the result of healthier people being able to be more productive in the labor market. Or most likely, each of these factors as well as additional considerations drive the relationship.

When we examine the correlates of mortality (at ages 75 or 80 ) in a reduced form regression, only a small number of covariates are consistently significant: the survival gradient with respect to lifetime income quintiles is positive, but not statistically significant. Education is also not significantly correlated with survival. Rather, males, smokers, and beginning-of-sample health conditions, such as heart and lung problems or having functional difficulties are significantly, negatively correlated with survival. Of 
course, the health conditions are not exogenous to survival probabilities (though we measure them in the first available sample year). When we drop the initial health conditions from the regressions, being in the highest lifetime wealth quintile and having more than a high school degree are significantly, positively correlated with survival to age 80 . As in the previous specifications, survival is negatively correlated with smoking and with being male.

To summarize, there is a clear relationship between lifetime income and survival. There are many likely explanations for the patterns. We write down and solve a model that captures several of these explanations, though we do not model differences in innate ability to produce health capital. Households in the model have different, exogenous draws on annual earnings, and hence different lifetime incomes. They differ in the timing of exogenous marriage and fertility. Given differences in incomes and demographic characteristics, they will respond to health shocks (which vary by lifetime income), earnings shocks, and government programs in different ways. Moreover, we allow consumption and health to be gross complements or gross substitutes in utility. The work that follows, therefore, illuminates the channels through which health, consumption, and wealth are related.

\subsection{Health production}

The first issue we need to confront when modelling the interplay of health and intertemporal consumption decisions is to decide how to model health. The most straightforward approach, borrowing from Grossman (1972), is to allow investment in medical care to affect health production (where health, in turn, is an argument of utility). As noted above, however, there is at best mixed evidence that marginal expenditures on medical care in the U.S. buy greater health (and hence longevity). This phenomenon is sometimes referred to as "flat of the curve" medicine. Evidence comes from the Dartmouth Health Atlas (http://dartmouthatlas.org/) and Finkelstein and McKnight 
(2008), among others.

It is noteworthy just how hard scholars need to look to find evidence that expenditures on medical care have a discernible, positive effect on health and particularly mortality outcomes. Card, Dobkin, Maestas (2008), for example, is one of a small number of studies that find expenditures are positively correlated with survival. Their work is based on a very large sample of people admitted to emergency rooms in California: they find the positive effects of spending apply to a small subset of the conditions that lead people to show up in emergency rooms. Doyle (2010) shows that men who have heart attacks when vacationing in Florida have higher survival probabilities if they end up being served by high- rather than low-expenditure hospitals. Despite these two welldone studies, we need to be careful when modelling the effect of out-of-pocket medical expenditures on health production. Numerous studies suggest significant portions of medical expenditures have little discernible effect on health.

Factors such as time spent exercising, smoking decisions, and diet appear to play a not-insignificant role in determining health status and hence longevity. As the figure below suggests, for example, exercise is strongly, positively correlated with lifetime income in the 3 years used for our primary sample. Nevertheless, the computational demands that arise in solving our dynamic programming model household-by-household with endogenous consumption and health production decisions requires us to be parsimonious in our modelling of health. Given these considerations, we monetize all health-producing activities. The essential tradeoff in the model is between health investments and consumption. For working households, time spent in exercise can be thought of as reducing hours available for income-producing opportunities, and therefore reducing consumption possibilities. 


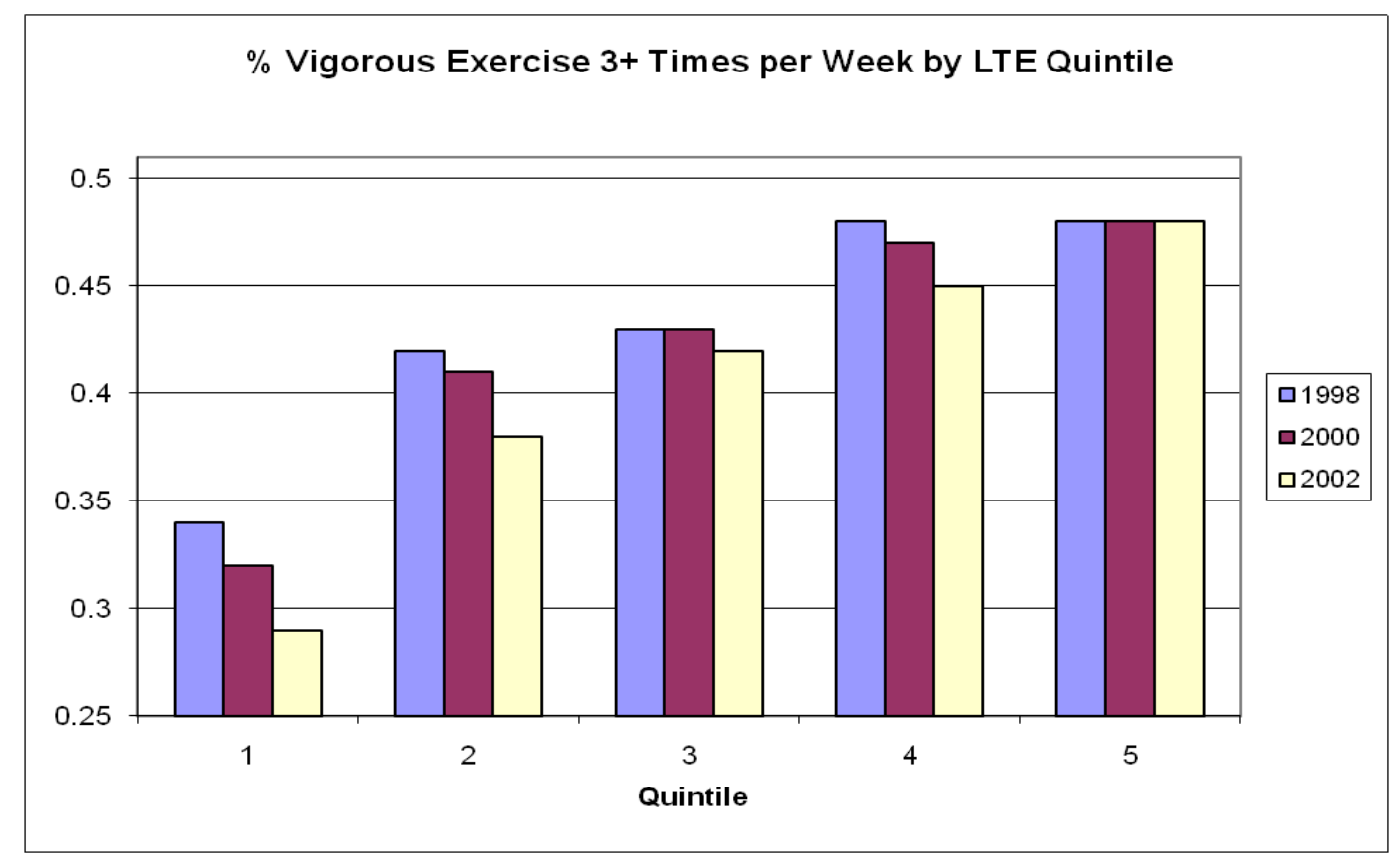

For retired households: i.e., those drawing their income from pensions, social security, and non-labor income, non-monetary expenditures on health production reduce leisure. We model (for both working and retired households) a combined time and financial budget constraint, which we describe in greater detail below. In this way, we recognize that there is an opportunity cost to health-related investments for working and retired households. Hence, our model captures the essential tradeoff between non-health related consumption and health investment.

\section{Model Economy}

Households in our model derive utility from health and consumption. We simplify the household's intertemporal problem by treating labor supply and retirement as being exogenous. While earnings are assumed to be exogenous, the expectations households have about annual earnings realizations have an important effect on optimal consumption and health investment. We specify earnings expectations using data on annual earnings 
realizations from the HRS (from the restricted social security data). Even though adding health capital involves only one additional choice variable (relative to a standard lifecycle intertemporal consumption problem), it is a significant complication. In addition to affecting longevity, households derive direct satisfaction from health.

We assume a household maximizes utility by choosing consumption and health investments:

$$
E\left[\sum_{j=S}^{\infty} \beta^{j-S} n_{j} U\left(c_{j} / n_{j}, l_{j}, h_{j}\right)\right]
$$

The expectation operator $E$ denotes the expectation over uncertain future earnings and uncertain health shocks, $\beta$ is the discount rate, $j$ is age, $S$ is the age that a household member entered the labor market, $c$ is consumption, and $h$ is health and $l$ stands for leisure. $n_{j}$ represents the equivalent number of adults in the household and is a function of the number of adults, $A$, and children, $K$, in the household $g\left(A_{j}, K_{j}\right)$.

An innovation of this paper is that we model the determinants of life expectancy. We assume that the household possesses a health stock and investments in the health stock prolong life. The accumulation process of the stock of health is given by

$$
h_{j+1}=f\left(m_{j}, i_{j}\right)+\left(1-\delta_{h}\right) h_{j}+\varepsilon_{j}, j \in\{S, \ldots\}
$$

The above equation represents the evolution of health status $h_{j}$ across ages. The stock of health in the next age $h_{j+1}$ is determined by the production of health, given by $f\left(m_{j}, i_{j}\right)$. Health capital is produced using time, $i_{j}$, which could be exercise or other health-producing activities, and medical expenditures as inputs. Households spend an indivisible amount of time $\omega$ working each period and spend the rest of their time endowment $1-\omega$ on either leisure or on activities that augment health investments. Upon retirement, households split their time endowment of 1 unit between leisure and health investments. Total medical expenditures $m_{j}$ are a function $M(\cdot)$ of out of pocket 
medical expenses, $m_{j}^{o o p}$. In the above equation, $\delta_{h}$ stands for the depreciation rate of health. Introducing age-dependent shocks to health is both realistic and necessary if we are interested in matching biological processes and the data. These age-dependent shocks are denoted by $\varepsilon_{j}$. In typical lifecycle models, medical expenditures have only financial consequences. Here medical expenditures affect health capital which, in turn, affects utility and longevity. The modeling approach mimics the modeling of human capital - additions to human capital can be either consumption or investment as in Becker (1964), Mincer (1974) and the subsequent, vast human capital literature.

The probability of surviving into the next period is given by the function $\Psi(h)$. This function satisfies two properties. As $h$ goes to $\infty, \Psi(h)$ converges to 1 . Second, $\Psi(h)=0$ for $h \leq 0$. This ensures that as soon as $\mathrm{h}$ goes to zero, the household dies. Finally, note that health status affects utility directly.

Consumption and the age of retirement are chosen to maximize expected utility subject to the constraints.

$$
\begin{gathered}
y_{j}=e_{j}+r a_{j}+T\left(e_{j}, a_{j}, j, n_{j}\right), j \in\{S, \ldots, R\} \\
y_{j}=S S\left(\sum_{j=S}^{R} e_{j}\right)+D B\left(e_{R}\right)+r a_{j}+T_{R}\left(e_{R}, \sum_{j=S}^{R} e_{j}, a_{j}, j, n_{j}\right), j \in\{R+1, \ldots\} \\
c_{j}+a_{j+1}+m_{j}=y_{j}+a_{j}-\tau\left(e_{j}+r a_{j}\right), j \in\{S, \ldots, R\} \\
c_{j}+a_{j+1}+m_{j}=y_{j}+a_{j}-\tau\left(S S\left(\sum_{j=S}^{R} e_{j}\right)+D B\left(e_{R}\right)+r a_{j}\right), j \in\{R+1, \ldots\}
\end{gathered}
$$

In these expressions $y$ is income, $e$ is earnings, $a$ is assets, $r$ is the interest rate, $T$ is a transfer function, and $R$ is the age of retirement. Social security $(S S)$ is a function of lifetime earnings, defined benefit pensions $(D B)$ are a function of earnings in the last year of life, $\tau$ is a payroll and income tax function, and the transfer function for retirees 
$\left(T_{R}\right)$ is a function of social security, DB pensions, assets, age, and family structure.

\subsection{Retired Household's Dynamic Programming Problem}

A retired household after age $R$ obtains income from social security, defined benefit pensions, and preretirement assets. The dynamic programming problem at age $j$ for a retired household is given by

$$
V\left(e_{R}, E_{R}, a, j, h\right)=\max \left\{n U(c / n, 1-i, h)+\beta \Psi(h) \int V\left(e_{R}, E_{R}, a, j+1, h^{\prime}\right) d \Xi(\varepsilon)\right\}
$$

subject to

$$
\begin{gathered}
y=S S\left(E_{R}\right)+D B\left(e_{R}\right)+r a+T_{R}\left(e_{R}, E_{R}, a, j, n\right) \\
c+a^{\prime}+m^{o o p}=y+a-\tau\left(S S\left(E_{R}\right), D B\left(e_{R}\right)+r a\right) \\
h^{\prime}=F\left(M\left(m^{o o p}\right), i\right)+\left(1-\delta_{h}\right) h+\varepsilon
\end{gathered}
$$

In the above equation the value function, $V\left(e_{R}, E_{R}, a, j, h\right)$, denotes the present discounted value of maximized utility from age $j$ until the date of death, the ' superscript denotes the corresponding value in the following year; and, as noted before, $\Psi(h)$ denotes the probability of survival between ages $j$ and $j+1$ for the husband and the wife respectively. $m^{o o p}$ are out of pocket medical expenses. Total earnings up to the current period are denoted by $E_{R}$ while the last earnings draw at the age of retirement is $e_{R}$. Note that these values do not change once the household is retired.

\subsection{Working Household's Dynamic Programming Problem}

A working household between the ages $S$ and $R$ obtains income from labor earnings and preretirement assets. The dynamic programming problem at age $j$ for a working 
household is given by

$$
V\left(e, E_{-1}, a, j, h\right)=\max \left\{n U(c / n, 1-\omega-i, h)+\beta \Psi(h) \int V\left(e^{\prime}, E, a^{\prime}, j+1, h^{\prime}\right) d \Xi(\varepsilon)\right\}
$$

subject to

$$
\begin{gathered}
y=e+r a+T(e, a, j, n) \\
c+a^{\prime}+m^{o o p}=y+a-\tau(e+r a) \\
h^{\prime}=F\left(M\left(m^{o o p}\right), i\right)+\left(1-\delta_{h}\right) h+\varepsilon
\end{gathered}
$$

$V\left(e, E_{-1}, a, j, h\right)$ denotes the present discounted value of lifetime utility at age $j$. $E_{-1}$ are cumulative earnings up to the current period. The other variables are defined above.

\section{Model Parameterization and Calibration}

In this section we specify functional forms and parameter values that we use to solve the model. We start by specifying functional forms for utility and health production. We then set some parameter values based on information from the literature or from reduced form estimates from the HRS. We identify the other model parameters by fitting the predictions of the model for the average household to data on wealth accumulation, medical expenses and survival probabilities. Once we have these parameter values, we then solve the model household-by-household to examine predictions for every household in our sample.

Preferences: We assume households have constant relative risk-averse preferences. We further assume the subutility function over consumption and health has a constant 
elasticity of substitution. Hence the period utility takes the form

$$
U(c, h)=\frac{\left[\lambda\left(c^{\eta} l^{1-\eta}\right)^{\rho}+(1-\lambda) h^{\rho}\right]^{\frac{1-\gamma}{\rho}}}{1-\gamma} .
$$

The elasticity of substitution between the consumption-leisure composite and health is $1 /(1-\rho)$. The parameter $\gamma$ is the coefficient of relative risk aversion. Given that the choice of whether to invest in health and hence prolong life is endogenous, the coefficient of relative risk aversion $\gamma$ needs to be less than 1 . This guarantees that utility is a positive number. Similar assumptions are made in the endogenous fertility literature. The discount factor $(\beta)$ is set at 0.96 , a value similar to the 0.97 value used in Hubbard, Skinner, and Zeldes (1995); and Engen, Gale, and Uccello (1999). We also set $\eta=0.36$ from Cooley and Prescott (1995).

Equivalence Scale: This is obtained from Citro and Michael (1995) and takes the form

$$
g(A, K)=(A+0.7 K)^{0.7}
$$

where again, $A$ indicates the number of adults and $K$ indicate the number of children in the household.

Rate of Return: We assume an annualized real rate of return $(r)$ of 4 percent. This assumption is consistent with McGrattan and Prescott (2003), who find that the real rate of return for both equity and debt in the United States over the last 100 years, after accounting for taxes on dividends and diversification costs, is about 4 percent. As this project develops we will conduct additional sensitivity analysis on this parameter.

Taxes: We model an exogenous, time-varying, progressive income tax that takes the form

$$
\tau(y)=a\left(y-\left(y^{-a_{1}}+a_{2}\right)^{-1 / a_{1}}\right)
$$

where $y$ is in thousands of dollars. Parameters $a, a_{1}$, and $a_{2}$ are estimated by Gouveia 
and Strauss $(1994,1999)$ and characterize U.S. effective, average household income taxes between 1966 and 1989. We use the 1966 parameters for years before 1966 and the 1989 parameters for subsequent years. ${ }^{3}$

Earnings Process: Earnings expectations are a central influence on life-cycle consumption and health accumulation decisions, both directly and through their effects on expected pension and social security benefits. We aggregate individual earnings histories into household earnings histories. The household model of log earnings (and earnings expectations) is

$$
\begin{gathered}
\log e_{j}=\alpha^{i}+\beta_{1} A G E_{j}+\beta_{2} A G E_{j}^{2}+u_{j} \\
u_{j}=\rho u_{j-1}+\epsilon_{j}
\end{gathered}
$$

where, as mentioned above, $e_{j}$ is the observed earnings of the household $i$ at age $j$ in 2004 dollars, $\alpha^{i}$ is a household specific constant, $A G E_{j}$ is age of the head of the household, $u_{j}$ is an $\operatorname{AR}(1)$ error term of the earnings equation, and $\epsilon_{j}$ is a zero-mean i.i.d., normally distributed error term. The estimated parameters are $\alpha^{i}, \beta_{1}, \beta_{2}, \rho$ and $\sigma_{\epsilon}$.

We divide households into four groups according to education and the number of earners in the household, resulting in four sets of household-group-specific parameters. ${ }^{4}$ Estimates of the persistence parameters across groups range from 0.64 to 0.68 .

Transfer Programs: One purpose of this paper is to assess the importance of factors affecting health and household wealth, including the safety net. We model public income transfer programs using the specification in Hubbard, Skinner and Zeldes (1995). Specifically, the transfer that a household receives while working is given by

$$
T=\max \{0, \underline{c}-[e+(1+r) a]\}
$$

\footnotetext{
${ }^{3}$ In subsequent work we will update the parameters for tax changes since 1989.

${ }^{4}$ The groups are (1) married, head without a college degree, one earner; (2) married, head without a college degree, two earners; (3) married, head with a college degree, one earner; and (4) married, head with a college degree, two earners. A respondent is an earner if his or her lifetime earnings are positive and contribute at least 20 percent of the lifetime earnings of the household.
} 
whereas the transfer that the household receives upon retiring is

$$
T=\max \left\{0, \underline{c}-\left[S S\left(E_{R}\right)+D B\left(e_{R}\right)+(1+r) a\right]\right\}
$$

This transfer function guarantees a pre-tax income of $\underline{c}$, which we set based on parameters drawn from Moffitt (2002). Subsistence benefits for a one-parent family with two children increased sharply, from $\$ 5,992$ in 1968 to $\$ 9,887$ in 1974 (all in 1992 dollars). Benefits have trended down from their 1974 peak - in 1992 the consumption floor was $\$ 8,159$ for the one-parent, two-child family. Following Hubbard, Skinner, and Zeldes, this formulation implies that earnings, retirement income, and assets reduce public benefits dollar for dollar. ${ }^{5}$

Health production: We assume that the production of health is given by $F\left(M\left(m^{o o p}\right), i\right)=$ $\left(m^{\chi} i^{1-\chi}\right)^{\xi}$, where $m=M\left(m^{o o p}\right)$. Total medical expenditures are related to out-ofpocket medical expenditures by a linear function that varies by insurance status. Specifically, $m=\zeta\left(m^{o o p}\right)$, where $\zeta$ is 3.66 for the uninsured, 4.94 for those with employerprovided insurance, 3.08 for those with individual insurance, 4.74 for those with Medicaid, 3.32 for those with Medicare, 3.49 for those with Medicare and a supplemental policy, and 5.14 for those with insurance from the Veterans Administration.

Survival Probability: The survival function is given by the cumulative distribution function $\Psi(h)=1-\exp \left(-\psi h^{\theta}\right)$.

Health Shocks: At each age, we assume that there are two possible values for the health shocks: $\varepsilon_{h}$ and $\varepsilon_{l}$. The first shock $\varepsilon_{h}$ corresponds to being healthy and is set to zero. The magnitude of the health shock $\varepsilon_{l}$ is determined by the calibration procedure. The probability of the second shock is assumed to vary by age: $p_{60}, p_{70}, p_{80}, p_{90}$ and $p_{100}$ refer to probabilities of 'bad' health shock between the ages of 0-60, 60-70, 70-80, 80-90 and $90+$ respectively.

\footnotetext{
${ }^{5}$ In subsequent work we will extend the benefit series to more recent years covered in our data.
} 


\subsection{Calibration}

While many parameters are set based on estimates from the literature or by estimating reduced form empirical models from the HRS, additional critical parameters still need to be specified. We use information on asset holdings, life tables and average medical expenses for the average household in the HRS to pin down these parameters. The parameters we calibrate are $\lambda, \rho, \gamma, \psi, \theta, \xi, \varepsilon_{l}, \chi, \delta_{h}, p_{60}, p_{70}, p_{80}, p_{90}$ and $p_{100}{ }^{6}$ To calculate these remaining parameters, we solve the dynamic programming problem for the average household - the household with average earnings over their lifetime. We then use the decision rules in conjunction with observed histories of earnings to obtain model predictions. Notice that while we have earnings observations on an annual basis, we only have medical expenses in 1998, 2000 and 2002. Hence we integrate out the lifetime sequence of health shocks before arriving at the model predictions for a given age. We then seek to obtain the best fit between model and data relative to the moments we seek to match. The moments we use to identify and pin down the parameters are:

1. Mean net worth in 1998 (age 65.3) is $\$ 346,221$

2. Probability of dying age 54 and under: $0.62 \%$

3. Probability of dying $60-64: 4.34 \%$

4. Probability of dying 70-74: $9.84 \%$

5. Probability of dying 75-79: $11.84 \%$

6. Probability of dying $80-84: 19.35 \%$

\footnotetext{
${ }^{6}$ To remind readers, these are $\lambda$ (the utility weight on consumption relative to health), $\rho$ (determines the elasticity of substitution between consumption and health), $\gamma$ (the coefficient of relative risk aversion), $\psi$ (the coefficient on health in the survival function), $\theta$ (the curvature of the survival function with respect to health), $\xi$ (the curvature of the health production function), $\varepsilon_{l}$ (the magniture of the "bad" health shock), $\chi$ (the share parameter in health production between monetary and time inputs), $\delta_{h}$ (the annual depreciation rate of health), and $p_{60}, p_{70}, p_{80}, p_{90}$ and $p_{100}$ (the probabilites of bad health shocks occuring at different age intervals).
} 
7. Probability of dying 90-94: $41.73 \%$

8. Probability of dying in the next 5 years for those 95 and older: $72.73 \%$

9. Average total medical expenses under age 52: $\$ 16,771$

10. Average total medical expenses for ages 53-57: $\$ 18,705$

11. Average total medical expenses for ages $63-67$ : $\$ 19,852$

12. Average total medical expenses for ages 73-77: $\$ 20,396$

13. Average total medical expenses for ages $83-87$ : $\$ 22,880$

14. Average total medical expenses for ages 93 and older: $\$ 18,742$

Essentially, this represents 14 non-linear equations in 14 unknowns. We obtained an exact match between the model predictions and the moments above and the resulting parameter values are given in the Table below.

$\begin{array}{lllllllllllllll}\text { Parameter } & \lambda & \rho & \gamma & \psi & \theta & \xi & \varepsilon_{l} & \chi & \delta_{h} & p_{60} & p_{70} & p_{80} & p_{90} & p_{100} \\ \text { Value } & 0.85 & -7.2 & 0.86 & .0011 & 1.84 & 0.77 & -16.4 & 0.53 & 0.056 & 0.05 & 0.11 & 0.165 & 0.207 & 0.256\end{array}$

A few comments are in order. First notice that $\gamma$ is less than 1 and the resulting preferences are close to logarithmic. Recall that this parameter needs to be less than unity to guarantee that utility is a strictly positive number. Next, the elasticity of substitution between consumption (more precisely, the composite of consumption and leisure) and health is $\frac{1}{1-\rho}=0.12$. Consumption and health are complements, as found by Murphy and Topel (2006) and Finkelstein, Luttmer, and Notowidigdo (2009). The rate of depreciation of health is around $5.6 \%$. The share of goods in the production of health $\chi$ is 0.53 , suggesting that time and goods are both important in the production 
of health. The 'bad' health shock $\varepsilon_{l}$ takes on the value -16.4 , recall that the good health shock $\varepsilon_{h}$ is set to 0 . Finally, note that the probability of the bad health shock increases from around $5 \%$ for households below 60 years of age to $11 \%$ for households between 60 and 70 , to $16.5 \%$ for households between 70 and 80 , to $20.7 \%$ for households between 80 and 90 and to $25.6 \%$ to households above the age of 90 .

\subsection{Model Solution}

Once we have the calibrated parameters, we solve the dynamic programming problem by linear interpolation on the value function. For each household in our sample we compute optimal decision rules for consumption (and hence asset accumulation) and health investments from the oldest possible age (this is endogenous) to the beginning of working life $(S)$ for any feasible realizations of the random variables: earnings and health shocks. These decision rules differ for each household, since each faces stochastic draws from different earnings distributions (recall that is household specific). Householdspecific earnings expectations also directly influence expectations about social security and pension benefits. Other characteristics also differ across households. Consequently, it is not sufficient to solve the life-cycle problem for just a few household types.

\section{Results}

As emphasized in the previous discussion, we calibrate key model parameters to the average household in the data. The first question we address, therefore, is how the model matches the distribution of wealth and health spending. We examine this issue by showing median values by lifetime income. Lifetime income is defined within four roughly equal-sized age groups: under 60,60 to 65,66 to 75 , and over 75 . This relationship is given in the table below. 


\begin{tabular}{|l|c|c|c|c|}
\hline \multicolumn{1}{|c|}{1998} & \multicolumn{2}{|c|}{ Median Net Worth } & \multicolumn{2}{c|}{ Median Medical Expenses } \\
\hline & Data & Model & Data & Model \\
\hline \hline Bottom Lifetime Income Quintile & $\$ 35,978$ & $\$ 22,693$ & $\$ 5,181$ & $\$ 5,684$ \\
\hline Second Quintile & 69,534 & 46,680 & 5,794 & 6,783 \\
\hline Middle Quintile & 126,714 & 87,219 & 6,760 & 8,548 \\
\hline Fourth Quintile & 201,880 & 137,063 & 7,671 & 9,824 \\
\hline Highest Lifetime Income Quintile & 414,305 & 398,623 & 8,158 & 10,546 \\
\hline
\end{tabular}

As in Scholz, Seshadri, and Khitatrakun (2006), households are accumulating more wealth than the model suggests is optimal. The median medical expenses also seem to match fairly closely, though the gradient of total expenditures is less steep with respect to lifetime income in the data than it is in the model. The correlation of actual and optimal net worth is 0.74 . The correlation between actual medical expenditures and optimal medical expenditures in the model is 0.66 . The close correspondence between data and model predictions is striking, given that the model is fit only to the average household. We can summarize the match between model and data in the following two scatterplots, where we graph the ordered pair between actual and "optimal" net worth (from the model), and actual and optimal total medical expenditures. 


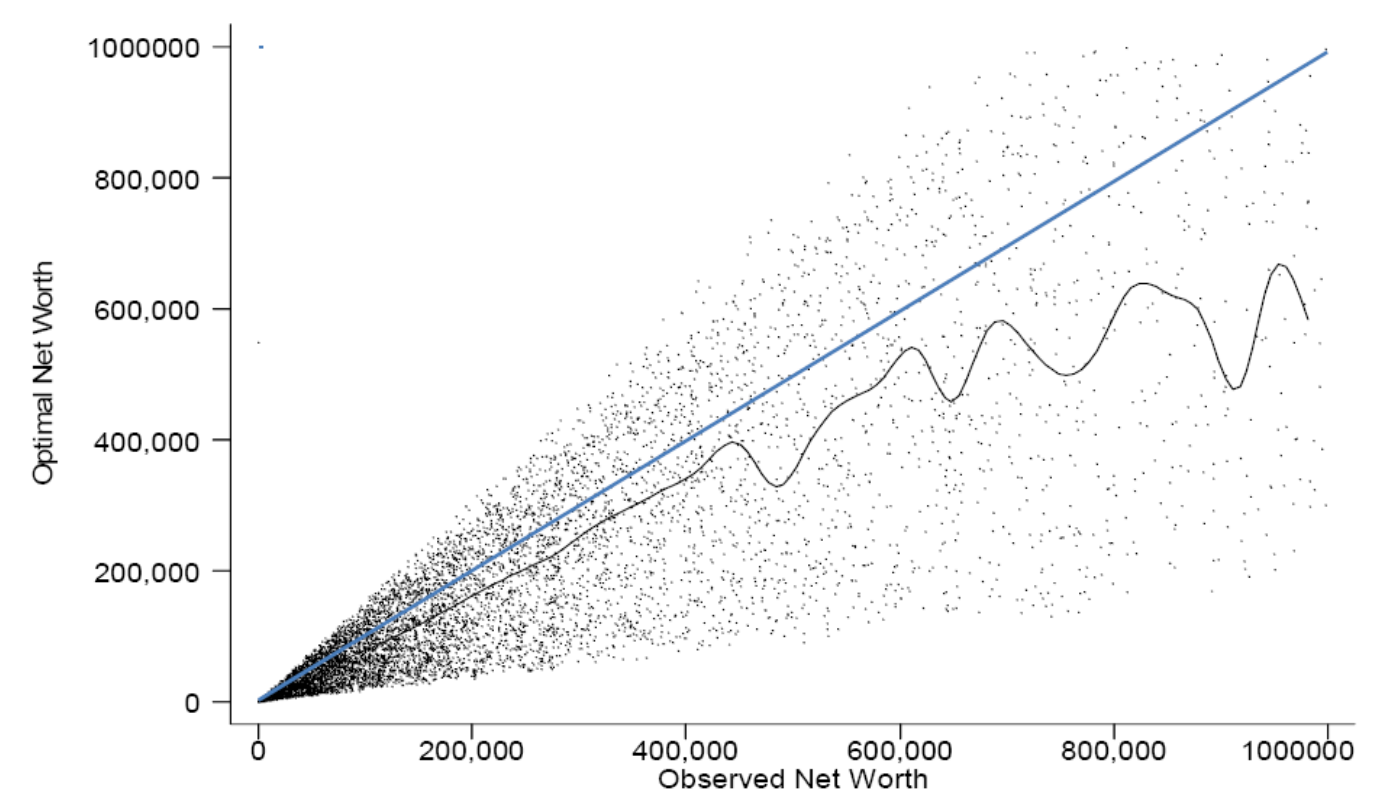

About 34 percent of the sample of net worth lies above the 45 degree line, indicating these households are saving less than the amount needed to equate the discounted marginal utility of consumption across time. The median shortfall, conditional on undersaving, is $\$ 23,543$. Our prior work described in Scholz, Seshadri, and Khitatrakun (2006) (for 1992, with only the original HRS cohort) found 16 percent of the HRS cohort was below their optimal target with the median shortfall being $\$ 5,600$. There are a number of differences between our earlier work and this paper, the three largest being that new cohorts have been added to the data and we are now looking at a later period; we have new estimates of the earning process, which show somewhat more volatility in earnings; and the model includes endogenous health production. In work not shown, we find the effects of the first two differences are larger than the effect of the third. But our earlier qualitative conclusion still holds: Most Americans seem to be preparing well for financially secure retirements. But the degree to which this is the case is less strong than our earlier work suggests. 


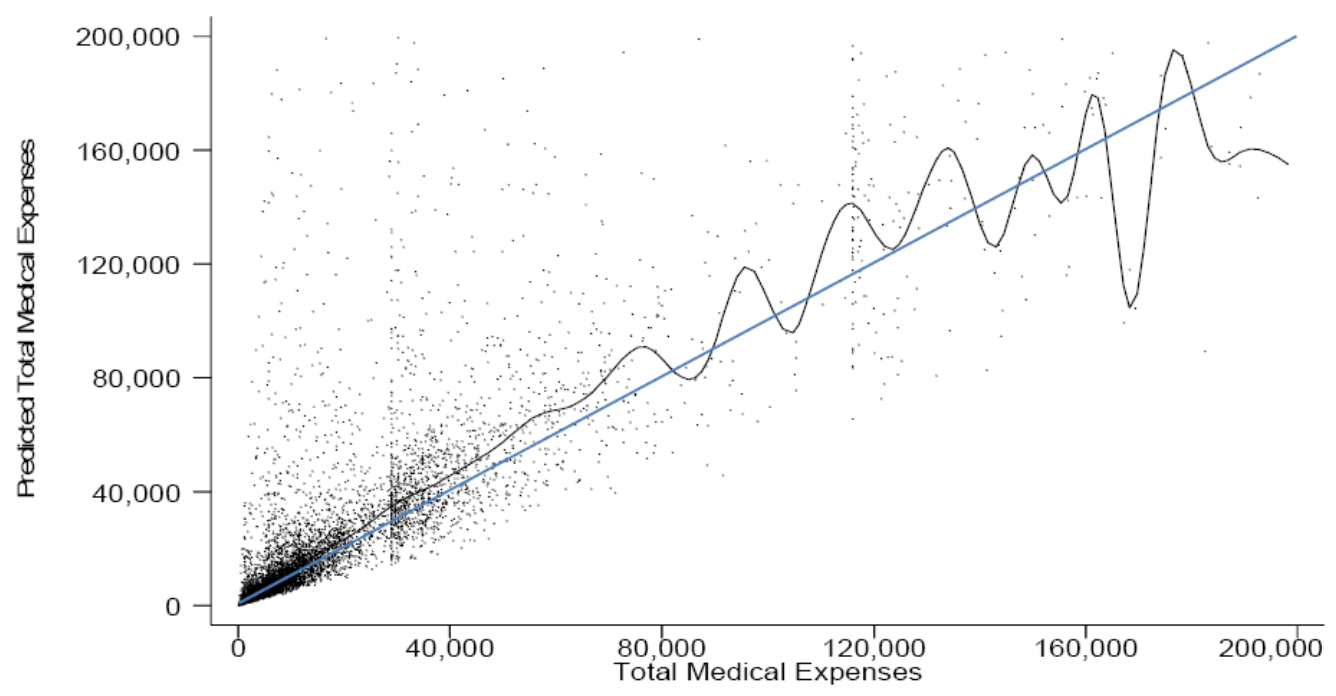

The scatterplot of medical expenses and fairly high correlation between actual and predicted medical expenses is also encouraging to us. The central tendency of the data (shown in the curved cubic spline) is close to the 45-degree line. We think the model does a good job matching two key elements of the data - net worth and medical spending.

\subsection{Mortality}

A novel feature of our economic model is that it allows us to examine the effects of policy changes on mortality. But the confidence readers have with our mortality results will depend, in part, on the ability of the model to reproduce mortality patterns in the HRS. To examine this, we take 10-year mortality probabilities in the HRS for two groups those who are 60 years old and those who are 75 years old. To operationalize this in the HRS (for the case of 60 year olds), we took everyone who entered the HRS in 1992, 1994 or 1996 and was in the age range 58 to 62 . We then examine their mortality over the subsequent 10 years. We make similar calculations for the age 75 sample. The entries in the table below under "Data" give the survival probabilities by lifetime 
income quintile.

\begin{tabular}{|l|l|l|l|l|}
\hline \multicolumn{1}{|c|}{ Survival Probabilities } & \multicolumn{2}{c|}{ Age 60 } & \multicolumn{2}{c|}{ Age 75 } \\
\hline & Data & Model & Data & Model \\
\hline \hline Bottom Lifetime Income Quintile & 0.75 & 0.73 & 0.51 & 0.50 \\
\hline Second Quintile & 0.79 & 0.75 & 0.53 & 0.52 \\
\hline Middle Quintile & 0.85 & 0.79 & 0.47 & 0.49 \\
\hline Fourth Quintile & 0.89 & 0.83 & 0.54 & 0.53 \\
\hline Highest Lifetime Income Quintile & 0.91 & 0.85 & 0.68 & 0.59 \\
\hline
\end{tabular}

The mortality calculations implied by the model require considerable calculation. For example, in the first two columns of the table we take all 60 year olds. These households face many different patterns of potential health shocks $\left(\varepsilon_{l}\right.$ paths). We integrate out over all potential sequences between the ages 60 and 70 and calculate the mass of survivors. These calculations require, of course, the optimal decision rules over the lifetime of households. We make similar calculations for households age 75 . The survival rates implied by the model are given in the table under the column "Model."

The model does a strikingly good job matching survival patterns in the underlying data, though we note that seven of the 14 moments that we use to calibrate the model tie down mortality probabilities by age for households with average lifetime incomes. This does not, however, imply that we would expect the model to reproduce survival patterns for high- or low-lifetime income quintile households. The most important deviations between the survival data and predictions occur for households in the highest lifetime income quintiles. These are likely to be the households that are most efficient in producing health capital. 


\subsection{Medicare and longevity}

To illustrate the potential usefulness of our preliminary model, we do some suggestive calculations of the effects of removing Medicare, the universal social insurance program that was established in 1965 to provide health insurance to the elderly. There are several reasons why we focus on this policy. First, Medicare is a massive social insurance program costing $\$ 325$ billion in fiscal year 2006. Second, end-of-life health shocks have been shown by several authors to have significant effects on asset accumulation. Third, Finkelstein and McKnight (2008) show in the first 10 years following the establishment of Medicare, there was no discernible effect on mortality. The effects of policy changes on mortality and asset accumulation in the short- and long-run are issues the model is nicely designed to address.

Suppose that Medicare were instantly eliminated and the change was not anticipated. All assets and health capital held by households had been accumulated under the assumption that Medicare would exist. After eliminating Medicare, we can recompute the model and examine the effects on 10-year survival probabilities.

\begin{tabular}{|l|l|l|l|l|}
\hline & \multicolumn{2}{|c|}{ Age 60 } & \multicolumn{2}{c|}{ Age 75 } \\
\hline & Baseline Model & No Medicare & Baseline Model & No Medicare \\
\hline \hline Bottom Income Quintile & 0.73 & 0.72 & 0.50 & 0.48 \\
\hline Second Lifetime Quintile & 0.75 & 0.74 & 0.52 & 0.50 \\
\hline Middle Lifetime Quintile & 0.79 & 0.79 & 0.49 & 0.48 \\
\hline Fourth Lifetime Quintile & 0.83 & 0.83 & 0.53 & 0.53 \\
\hline Highest Income Quintile & 0.85 & 0.85 & 0.59 & 0.59 \\
\hline
\end{tabular}

As can be seen from the Table, the short run effect on mortality of eliminating Medicare are trivially small. This suggests the possibility that if Medicare affects mortality, its influence must occur over the lifecycle. Since most accumulation of health capital and wealth occurs well before retirement, health status is largely fixed by age 60-65. Eliminating Medicare, therefore, has little effect on health in the years immedi- 
ately following its repeal. While Medicare does provide insurance against adverse health shocks, our model yields results consistent with the empirical findings of Finkelstein and McKnight: eliminating Medicare would have a small effect on 10-year survival probabilities immediately following repeal.

The long-run effect of Medicare repeal We now look at the long-run effect of repealing Medicare, comparing model predictions for assets and survival in worlds with and without Medicare. We first look at the effects of repealing Medicare on long-run mortality patterns. Perhaps surprisingly, in light of the previous results, Medicare repeal now has a large effect on survival probabilities, particularly in the lowest lifetime income quintile. In the long-run, a forward-looking household with low lifetime income will recognize they have no health insurance program in retirement. They also correctly anticipate the lifecycle pattern of health shocks and the cumulative effects of health depreciation, so old-age health status will be worse than health status at younger ages. Because health and consumption are complements, the life-cycle pattern of consumption mirrors the lifecycle pattern of health. Low lifetime income households will therefore invest less in health, trading off a shorter expected lifespan for greater consumption in younger ages when the marginal utility of consumption is high relative to later in life. High lifetime income households can mitigate these effects by self-insuring: they engage in buffer stock saving and invest in health capital.

\begin{tabular}{|l|l|l|l|l|}
\hline & \multicolumn{2}{|c|}{ Age 60 } & \multicolumn{2}{c|}{ Age 75 } \\
\hline & Baseline Model & No Medicare & Baseline Model & No Medicare \\
\hline \hline Bottom Lifetime Income Quintile & 0.73 & 0.66 & 0.50 & 0.44 \\
\hline Second Quintile & 0.75 & 0.72 & 0.52 & 0.46 \\
\hline Middle Quintile & 0.79 & 0.76 & 0.49 & 0.42 \\
\hline Fourth Quintile & 0.83 & 0.82 & 0.53 & 0.52 \\
\hline Highest Lifetime Income Quintile & 0.85 & 0.84 & 0.59 & 0.58 \\
\hline
\end{tabular}


The effects of this experiment on wealth are shown in the table below. With Medicare eliminated and many elderly people paying for all medical care out of pocket, some households engage in additional buffer stock saving, self-insuring in the absence of Medicare (some still have insurance provided by Medicaid, employer-provided plans, or VA-Champus). Indeed, we see greater wealth accumulation throughout the lifetime income distribution. We also see fewer medical expenditures. The tables illustrate clearly a central insight into the lifecycle model with endogenous health. Long-run adjustments to changes in the institutional environment will be made on two margins: first, households will consume less and do more buffer stock saving. Second, private health investment will decrease. The result is that households will both consume less and die earlier than in a world without Medicare. But relative to a standard lifecycle model of consumption without endogenous health production, the consumption responses will be smaller, since a portion of the response occurs through a diminution of health capital. With less health capital, households correctly anticipate that they will die younger and hence they need to accumulate less wealth to finance consumption in retirement. Thus, the model with endogenous health mitigates the effects of changes in social insurance on consumption relative to standard lifecycle models.

\begin{tabular}{|l|c|c|c|c|}
\hline \multicolumn{1}{|c|}{1998} & \multicolumn{2}{c|}{ Median Net Worth } & \multicolumn{2}{c|}{ Median Medical Expenses } \\
\hline \multicolumn{1}{|c|}{ Lifetime Income } & Model & No Medicare & Model & No Medicare \\
\hline \hline Bottom Lifetime Income Quintile & $\$ 22,693$ & $\$ 49,475$ & $\$ 5,684$ & $\$ 2,891$ \\
\hline Second Quintile & 46,680 & 68,392 & 6,783 & 4,373 \\
\hline Middle Quintile & 87,219 & 114,374 & 8,548 & 7,157 \\
\hline Fourth Quintile & 137,063 & 176,304 & 9,824 & 8,717 \\
\hline Highest Lifetime Income Quintile & 398,623 & 449,485 & 10,546 & 9,214 \\
\hline
\end{tabular}




\section{Conclusion}

In this paper we describe our initial efforts to develop a lifecycle model with endogenous investment in health. We solve the model household-by-household using data from the HRS. We force the model to match moments on wealth, mortality and medical expenses for the average HRS household. It nevertheless does a nice job matching the distribution of wealth and survival across lifetime income quintiles. We use the model to study the effects of public policy on wealth accumulation and mortality. The longrun goal of this research project is to illuminate the tradeoffs households may make in consumption and health when confronted with exogenous shocks or policy changes. We find substantial long-run tradeoffs between consumption and health investment in response to eliminating the stylized Medicare program in our model, and the responses we document have implications for longevity. But we also note that our work is very preliminary. 


\section{References}

[1] Becker, G. S., 1964, Human Capital : A Theoretical and Empirical Analysis, with Special Reference to Education. New York: National Bureau of Economic Research.

[2] Card, David, Carlos Dobkin, Nicole Maestas, "Does Medicare Save Lives?" Quarterly Journal of Economics, May 2009, Vol. 124, No. 2: 597-636.

[3] Case, Ann and Angus Deaton, "Broken Down by Work and Sex: How Our Health Declines," in D. Wise (ed.) Advances in the Economics of Aging. University of Chicago Press, 2005.

[4] Citro, Constance F. and Robert T. Michael. 1995. Measuring Poverty: A New Approach. Washington, D.C.: National Academy Press.

[5] Cooley, Thomas F. and Ed Prescott, 1995, "Economic Growth and Business Cycles," Chapter 1 in T. F. Cooley, ed., Frontiers of Business Cycle Research, (Princeton University Press), 1-38.

[6] De Nardi, Mariacristina, Eric French, and John Bailey Jones, 2010, "Why Do the Elderly Save? The Role of Medical Expenses," Journal of Political Economy

[7] Doyle, Joseph J, Jr, "Returns to Local-Area Health Care Spending: Using Health Shocks to Patients Far from Home," May 2009. http://www.mit.edu/ jjdoyle/doyle_vacation_aer_may2009.pdf

[8] Engen, Eric M., William G. Gale and Cori R. Uccello. 1999. "The Adequacy of Retirement Saving." Brookings Papers on Economic Activity 2: 65-165.

[9] Finkelstein, Amy, Erzo Luttmer, and Matthew Notowidigdo, 2009, "What Good is Wealth without Health? The Effect of Health on the Marginal Utility of Consumption," NBER Working Paper No. 14089, (revised). 
[10] Finkelstein, Amy and Robin McKnight, 2008, "What Did Medicare Do? The Initial Impact of Medicare on Mortality and Out of Pocket Medical Spending," Journal of Public Economics, 92, 1644-1669.

[11] Fonseca, Raquel, Pierre-Carl Michaud, Titus Gamama, and Arie Kapteyn, 2009, "On the Rise of Health Spending and Longevity," IZA Discussion paper \#4622

[12] Gouveia, Miguel and Robert R. Strauss. 1994. "Effective Federal Individual Income Tax Functions: An Exploratory Empirical Analysis." National Tax Journal 47(2) (June): 317-39.

[13] Gouveia, Miguel and Robert R. Strauss. 1999. "Effective Tax Functions for the U.S. Individual Income Tax: 1966-89." Proceedings of the 92nd Annual Conference on Taxation, National Tax Association: 155-65.

[14] Grossman, Michael, 1972, "One the Concept of Health Capital and the Demand for Health," Journal of Political Economy, 80, 223-255

[15] Hubbard, Glen R., Jonathan Skinner, and Stephen P. Zeldes. 1995. "Precautionary Saving and Social Insurance." Journal of Political Economy, 103(2) (April): 360-99.

[16] Kopecky, Karen and Tatyana Koreshkova, 2009, "The Impact of Medical and Nursing Home Expenses and Social Insurance Policies on Saving and Inequality," mimeo

[17] McGrattan, Ellen R. and Edward C. Prescott. 2003. "Average Debt and Equity Returns: Puzzling?" American Economic Review Papers and Proceedings. 93(2) (May): 392-397.

[18] Mincer, J., 1974, Schooling, Experience and Earnings, Columbia University Press, New York, 1974. 
[19] Modigliani, Franco and R. Brumberg. 1954. "Utility Analysis and the Consumption Function: An Interpretation of Cross Section Data." In Post-Keynesian Economics, K.K. Kurihara (ed.), pp. 388-436. New Brunswick, NJ: Rutgers University Press.

[20] Moffitt, Robert. 2002. "Documentation for Moffitt Welfare Benefits File." Manuscript, February 22, http://www.econ.jhu.edu/People/Moffitt/DataSets.html.

[21] Murphy, Kevin M. and Topel, Robert H. (2006). "The Value of Health and Longevity," Journal of Political Economy 114 (5):871-904.

[22] Palumbo, Michael G. 1999. "Uncertain Medical Expenses and Precautionary Saving Near the End of the Life Cycle." Review of Economic Studies 66(2): 395-421.

[23] Scholz, John Karl, Ananth Seshadri, and Surachai Khitatrakun. 2006. "Are Americans Saving 'Optimally' for Retirement?" Journal of Political Economy. August, 607-643.

[24] Smith, James P., "Consequences and Predictors of New Health Events," in D. Wise (ed.) Advances in the Economics of Aging. University of Chicago Press, 2005.

[25] Yogo, Motohiro, 2009, "Portfolio Choice in Retirement: Health Risk and the Demand for Annuities, Housing, and Risky Assets," mimeo 